\title{
Structural features and activity of Brazzein and its mutants upon substitution of a surfaced exposed alanine
}

\author{
Parisa Ghanavatian $^{\mathrm{a}}$, Khosrow Khalifeh ${ }^{\mathrm{b}}$, Vahab Jafarian ${ }^{\mathrm{a} *}$ \\ ${ }^{a}$ Laboratory of Biochemistry, Department of Biology, Faculty of Sciences, University of Zanjan, Zanjan. Iran \\ ${ }^{\mathrm{b}}$ Laboratory of Biophysics, Department of Biology, Faculty of Sciences, University of Zanjan, Zanjan. Iran
}

\begin{abstract}
Brazzein (Brz) is a member of sweet-tasting protein containing four disulfide bonds. It was reported as a compact and heat-resistant protein. Here, we have used site-directed mutagenesis and replaced a surface-exposed alanine with aspartic acid (A19D mutant), lysine (A19K mutant) and glycine (A19G mutant). Activity comparisons of wild-type (WT) and mutants using taste panel test procedure showed that A19G variant has the same activity as WT protein. However, introduction of a positive charge in A19K mutant led to significant increase in Brz's sweetness, while A19D has reduced sweetness compared to WT protein. Docking studies showed that mutation at position 19 results in slight chain mobility of protein at the binding surface and changing the patterns of interactions toward more effective binding of E9K variant in the concave surface of sweet taste receptor. Far-UV CD data spectra have a characteristic shape of beta structure for all variants, however different magnitudes of spectra suggest that beta-sheet structure in WT and A19G is more stable than that of A19D and A19K. Equilibrium unfolding studies with fluorescence spectroscopy and using urea and dithiothritol (DTT) as chemical denaturants indicates that A19G mutant gains more stability against urea denaturation; while conformational stability of A19D and A19K decreases when compared with WT and A19G variants. We concluded that the positive charge at the surface of protein is important factor responsible for the interaction of protein with the human sweet receptor and $\mathrm{Ala}^{19}$ can be considered as a key region for investigating the mechanism of the interaction of Brz with corresponding receptor.
\end{abstract}

Keywords: Brazzein; site-directed mutagenesis; sweetness; Docking, Equilibrium; interaction

${ }^{*}$ Corresponding author.

E-mail address: V.Jafarian@znu.ac.ir (V. Jafarian). 


\section{Introduction}

In recent years, demands for natural and healthy sweeteners with low calorie instead of traditional sweeteners like sucrose have been increased. So the need for sweet tasting proteins as alternative sweeteners seems to be essential in food industry[1]. Among all sweet tasting proteins, Brazzein (Brz) as one of the smallest protein is an appropriate model protein for both academic studies and food industry considering its specific features such as high level of sweetening potency, thermo stability and wide range of $\mathrm{pH}$ tolerability [2-4]. It has a compact structure containing four disulfide bonds which exists in two forms; namely major and minor structures with 54 and 53 residues, respectively [5].

The structural data of major structure includes crystal (PDB code: 4HE7) and solution state structures (PDB codes: 1BRZ and 2BRZ). Other reported structures include four solution-NMR structures of minor form (pdb codes: 2LY5, 2LY6, 2KYQ, 2KGQ). Its solution structure with nuclear magnetic resonance spectroscopy (pdb code: 2BRZ) indicates that it consists of three strands of antiparallel beta-sheet and a short alpha-helix joined together by loops. However, an additional $\alpha$-helix was also reported in protein data bank (pdb codes: 4HE7, 2LY5) [6].

A brief review of previous studies reveals that majority of investigations have been conducted for determining of factors responsible for sweetening features of the protein [7-13]. Among them, more studies have been performed by means of site-directed mutagenesis to identify the key residues and regions of the protein which are important in the sweetening power of Brz [9, 14-17]. The majority of these investigations emphasized the importance of surfaced-exposed regions of protein and the proportion of its surficial charge to the whole length of protein. As an example, it was revealed that two regions of Brz including $\mathrm{C}$ and $\mathrm{T}$-terminals of the proteins and a flexible loop around $\mathrm{Arg}^{43}$ have an outstanding role in sweetening property [9, 12].

Furthermore, studies by combination of electrophysiological record and site-directed mutagenesis showed that the effect of charge on sweetening potency of Brz is much more than that of side chain's length $[12,14]$. In addition, there are other reports about the relationship between sweetening power and intera-molecular hydrogen bonds on the protein structure [8].

As we know, physico-chemical features of various amino acids including the size and kind of side chain are the key factors in determining the folding kinetics and thermodynamic stability [18]. Among them, hydrophobicity and hydrophilicity of the amino acids and their location on the protein structure are very important properties that can influence the conformational stability 
of dissolved proteins in polar environments[19]. In spite of various studies, few attempts have been performed on the structural features of Brz regarding its thermodynamic characterization and conformational stability.

According to the $1 \mathrm{H}, 15 \mathrm{~N}-\mathrm{HSQC}-\mathrm{NMR}$ studies on two variants of Brz it was recently shown that increasing the flexibility of protein may allow protein to interact more strongly with the Gprotein coupled human sweet receptor. They reported that substitution of Aspartic acid with Lysine (D40K) and increasing the net charge of protein toward positive charge (D40K mutant) leads to alterations in local conformational and dynamic of protein accompanied by three-fold enhancement of protein activity[20]. They also suggested that three regions of Brz known as sites 1, 2 and 3 are essential for interaction with sweet taste receptor.

We previously investigated the effect of charge alteration at position 9 (starting point of site 3) of Brz and found that changing the charge from negative to positive at the surface of protein can influence its sweetness power [21]. In this study, we designed three mutants of Brz using bioinformatics tools and substituted $\mathrm{Ala}^{19}$ (The end of site 3) by lysine (A19K mutant), Aspartic acid (A19D mutant) and glycine (A19G mutant). Upon construction of recombinant proteins, the sweetness of protein variants was measured by taste panel test. Structural properties and thermodynamic stability were also determined by fluorescence and circular dichroism spectroscopy as well as isothermal urea denaturation experiments. According to structural data and in spite of high thermos-stability of Brz, we found that the conformational stability of A19D and A19K mutants against chemical denaturant is lower than that of WT protein. It was also revealed that the A19K mutant has higher sweetness power in comparison with other proteins.

\section{Material and Methods}

\subsection{Materials}

E. coli strain SHuffle ${ }^{\circledR}$ from New England Biolabs (www.neb.com) and protein expression vector pET-28a (+) used in this study were supplied by Novagen (Novagen, Madison, WI, USA). Synthesis of the DNA primers for mutagenesis and DNA sequencing was performed by bioneer (Korean). PCR Purification and Plasmid Extraction Kits were purchased from Bioneer (UK). Phenylmethylsulfonyl fluoride (PMSF) (Sigma-Aldrich, USA), DpnI (Thermo Scientific, 
USA) with other chemicals and reagents were commercially available as the highest reagent grade.

\subsection{Preparation of brazzein mutants by site-directed mutagenesis}

In this study, minor form of Brz (GenBank: KF013250.1) with 53-amino acid containing Met residue in N-terminus was cloned in pET28a vector (Fig. 1).

The primers required for inducing the mutations are provided in Table 1. Site directed mutagenesis was performed through Quick-change method using Pfu premix Kit (Bioneer, Korea). Before the transformation and in order of digesting non-mutated template plasmids, the PCR products were treated with $15 \mathrm{U}$ DpnI at $37^{\circ} \mathrm{C}$ for $18 \mathrm{~h}$ and purified by clean up kit to remove the digested fragments and primers. A value of $2 \mu \mathrm{l}$ of the purified products was then used to transform the competent cells (Escherichia coli BL21 (DE3)) using calcium chloride procedure [22]. Finally, WT and mutated plasmids of Brz (pET-28a) were sequenced using an automated sequencer (Bioneer, Korean).

Fig 1:

Table 1:

\subsection{Expression and purification of WT and mutant protein}

A single colony of $E$. coli strain SHuffle ${ }^{\circledR}$ T7 Express containing plasmid pET-28a(+) was firstly selected and grown overnight at $30^{\circ} \mathrm{C}$ in $5 \mathrm{~mL}$ of Luria broth (LB) medium supplemented with $50 \mu \mathrm{g}$ kanamycin $/ \mathrm{mL}$ and continually was shaken at $180 \mathrm{rpm}$. Afterwards, $200 \mu \mathrm{L}$ of the mixture was injected into $200 \mathrm{~mL}$ Trypton Broth (TB) medium, containing $50 \mu \mathrm{g}$ kanamycin $/ \mathrm{mL}$, and then incubated at $30^{\circ} \mathrm{C}$ until an $\mathrm{A}_{600} \mathrm{~nm}$ of approximately $0.8-1.0$ was attained. Cells were subsequently induced for $2 \mathrm{~h}$ by addition of IPTG (Isopropyl- $\beta$-Dthiogalactopyranosid) at a final concentration of $0.5 \mathrm{mM}$. The culture was then centrifuged at $12000 \mathrm{~g}$ for $20 \mathrm{~min}$ at $4^{\circ} \mathrm{C}$ and deposited product were added to lysis buffer, $0.5 \mathrm{mM}$ PMSF and 4 mM DTT. The purification process was performed on Ni-NAT spin column (QIAGEN Co.) Finally, protein analysis was performed by $16 \%$ Tris-Tricine gel. Protein concentration was determined according to Bradford method [23]. The data were averaged of three independent experiments. 


\subsection{Cleavage of the fusion protein and purification of brazzein.}

The $\mathrm{pH}$ of the sample was adjusted slowly to $1.5-1.7$ by adding $1 \mathrm{M} \mathrm{HCl}$. Thirty to fifty $\mathrm{mg}$ $\mathrm{CNBr}$ was added into $8 \mathrm{ml}$ of elution buffer containing protein at $0.2 \mathrm{mg} / \mathrm{ml}$ concentration. In order to remove amino terminus, the solution was incubated under dark condition $(18 \mathrm{~h})$ at room temperature $[24,25]$. Ni-NTA column was used to separate cleavage, $\mathrm{CNBr}$-treated proteins from uncleavage ones. Condensation, desalting and buffer exchange of the protein were done by Amicon Ultra-0.5 Centrifugal column (Millipore, USA) and samples were used for further studies.

\subsection{Taste test}

The tests for the solutions of WT and mutants were carried out according to Lee et al procedure [26]. Distilled water (DW) and 1\% sucrose solution were used for comparison. For conducting the test 11 individuals including five men and six women aging 20-39 and with good health and normal sense were selected for tasting. As depicted in table 2, 200 $\mu \mathrm{L}$ of samples with desirable concentrations ranging from $1-10 \mu \mathrm{g} / \mathrm{ml}$ including $1,2,4,6,8$ and $10 \mu \mathrm{g} / \mathrm{ml}$ were delivered to apex of tongue by pipet [26]. After every test the mouth was washed by a cup of tap water and its sweetness was reported in scale of basic weight in comparison with sweetness of Sucrose. For comparison of sweetness power of a protein with Sucrose, the lowest quantity of Sucrose essential for sensing the sweetness $(1 \mathrm{gram} / \mathrm{ml})$ is divided by the lowest quantity of protein for similar sensing. The resulting parameter is reported as $\mathrm{g} / \mathrm{g}$. It can be converted to the minimum number of protein molecules for sweetness sensing using the following equation (21):

Number of molecules $=$

(Gram Sucrose/gram protein)*(molecular mass of protein/molecular mass of Sucrose)

The samples were used in order of increasing their concentration and the first sample in which each participant could detect its sweetness was considered as threshold of sensing. However, for preventing of any experimental bias, all participants in experiments as well as experiment conductors were not aware of the type of protein (WT or mutants) and the activity of protein variants were assayed using double-blind procedure. Each experiment was repeated three times in different days by the same participants. The resulting data were averaged and corresponding standard deviations were calculated. Differences among group means and their variations were evaluated by considering probability $\mathrm{P} \leq 0.05$ as the level of significance and performing 
analysis of variance (ANOVA) accompanied by pairwise comparisons of the scores of each group using Fisher's least significance difference (LSD) method.

\subsection{Bioinformatics}

Structural models of mutants as well as sweet taste receptor, T1R2/T1R3, were made with the MODELLER program Ver. 9.15 [27] and using the structure of WT protein (Pdb code: 2LY5) as template for mutants of Brz [4]. The Crystal structure of the extracellular region of the group II metabotropic glutamate receptor (pdb code: $2 \mathrm{E} 4 \mathrm{U}$ ) was also used as template for construction of sweet taste receptor [28]. The quality of structural models for each mutant was evaluated with the SVAES (The Structure Analysis and Verification Server) server [29-32] as well as the ModEval program at SaliLab Model Evaluation Server (https://modbase.compbio.ucsf.edu/evaluation//) [33-35] and the best structures were selected based on the scores of ERRAT and Verify 3D programs under the SAVES server and DOPE (Discrete Optimized Protein Energy) score of the ModEval program.

Accessible surface area of WT-Brz and its mutants was determined by VADAR (Volume, Area, and Dihydral Angle Reporter) server [36]. Examining the interactions of the structure of protein variants were performed by Protein Interaction Calculate (PIC) server using the pdb files of proteins as input [37].

To understand the molecular mechanism responsible for the recognition of binding residues, docking simulations were run using HADDOCK program (Ver. 2.2) [38]. The calculations on the protein side were guided by defining active residues based on the previous reports [16, 3940]. In order to find the possible external binding sites, the preferred models of HADDOCK were compared with previously reports and it was found that in the most of the complexes, the docking were done with the central region on the cavity between the T1R2-T1R3 receptor. Different predicted binding sites were energetically evaluated and the best one for each protein variant was selected and further analyzed.

\subsection{Circular dichroism measurements}

Circular dichroism (CD) spectra of the WT and mutants were recorded with an Aviv 215 circular dichroism spectrometer using a 1-mm path-length quartz cell and at $25^{\circ} \mathrm{C}$. Far-UV CD spectra were obtained at a protein concentration of $0.2 \mathrm{mg} / \mathrm{ml}$ at wavelengths from 190 to 250 
$\mathrm{nm}$. The measurements are expressed as mean residue ellipticity with a mean residue weight (MRW) of 118 for Brz. The data were recorded three to four times and averaged.

\subsection{Isothermal urea-induced denaturation}

For stability measurements, stock solution of urea $(10 \mathrm{M})$ was made in $50 \mathrm{mM}$ Tris, $\mathrm{pH}$ 7.6. For each unfolding experiment a fixed volume of protein stock solution $(50 \mu \mathrm{g} / \mathrm{ml})$ and $10 \mu \mathrm{l}$ Dithiothritole (DDT) was mixed with the appropriate volumes of buffer solution as well as fresh urea stock solution and were incubated for approximately $7 \mathrm{~h}$ at room temperature. Fluorescence measurements were performed with a Varian luminescence spectrophotometer. Intrinsic fluorescence was determined at excitation wavelength of $280 \mathrm{~nm}$. Emission spectra were recorded within $300-450 \mathrm{~nm}$ at the scan rate of $100 \mathrm{~nm}$ per minute. Both of the excitation and emission slits were set to $5 \mathrm{~nm}$.

\subsection{Analysis of isothermal urea-induced denaturation curves}

It was shown that the free energy of chemical unfolding reaction in small proteins in the presence of urea, $\Delta \mathrm{G}$ ([urea]) is linearly related to the concentration of denaturants as equation 1 [41]:

$$
\Delta \mathrm{G}([\text { urea }])=\Delta \mathrm{G}_{\left(\mathrm{H}_{2} \mathrm{O}\right)}-\mathrm{m}([\text { urea }])
$$

Where, $\Delta \mathrm{G}_{(\mathrm{H} 2 \mathrm{O})}$ is the free energy change of unfolding reaction extrapolated to zero concentration of urea and $\mathrm{m}$ is the slope of $\Delta \mathrm{G}$ versus [urea]. $\mathrm{m}$-value is a constant which is proportional to increase in the solvent accessible surface area upon unfolding of protein.

Hence, the free energy of unfolding in the absence of Urea, $\Delta \mathrm{G}_{(\mathrm{H} 2 \mathrm{O})}$ is calculated using equation 2:

$$
\Delta \mathrm{G}_{\left(\mathrm{H}_{2} \mathrm{O}\right)}=\mathrm{m}([\text { urea }])_{50 \%} \quad(2)
$$

[Urea $]_{50 \%}$ is the concentration of urea in which half of the protein is denatured.

Isothermal urea-induced denaturation data were analyzed for obtaining thermodynamic parameters of equation 1 and 2. The observed signal of characteristic maximum fluorescence emission was plotted as a function of Urea concentration. The resulting sigmoid-like curves known as urea denaturation curves determined at temperature $\mathrm{T}$ were first normalized between 01 and expressed as the plots of the fraction of protein in the unfolded state $\left(f_{\mathrm{u}}\right)$ versus [Urea]. The 
plots of $\left(f_{\mathrm{u}}\right)$ versus [Urea] were fitted to the equation 3, assuming a two-state (Folded-Unfolded) model with Kaliedagraph analysis software.

$$
\mathrm{F}_{\mathrm{U}}=\frac{\exp \left(\frac{-\left(\Delta \mathrm{G}_{\mathrm{H}_{2} \mathrm{O}}+\mathrm{m}[\text { Urea }]\right)}{\mathrm{RT}}\right.}{1+\exp \left(\frac{-\left(\Delta \mathrm{G}_{\mathrm{H}_{2} \mathrm{O}}+\mathrm{m}[\text { Urea }]\right)}{\mathrm{RT}}\right.}
$$

Where; $F_{U}$ is the measured fluorescence intensity as a function of urea concentration normalized between 0 and $1, \mathrm{R}$ is the gas constant and $\mathrm{T}$ is the temperature in Kelvin, $\Delta \mathrm{G}_{\mathrm{H}_{2} \mathrm{O}}$ is the free energy change of unfolding reaction extrapolated to zero concentration of urea and $\mathrm{m}$ is the slope of $\Delta \mathrm{G}$ versus [urea].

According to equation 2 and using $\Delta \mathrm{G}_{\mathrm{H}_{2} \mathrm{O}}$ and m-value obtained from equation 3, [Urea $]_{50 \%}$ can also be calculated $[42,43]$.

\section{Results}

\subsection{Description of mutation}

Fig. 2 shows the structure of WT-Brz in solution state (pdb code: 2LY5) and crystal form (pdb code: 4HE7). The main difference of two structures is due to the presence of a loop in solution structure as connector of the first beta strand with an alpha helix. In crystal form, however; presence of a short length sequence $\left(\mathrm{Q}^{17}-\mathrm{L}^{18}-\mathrm{A}^{19}-\mathrm{N}^{20}\right)$ in loop conformer results in breaking the helix into two fragments. The position of mutation is shown by arrow.

Fig. 2.

For determining the accessible surface area of residues in Brz we used VADAR program and aforementioned structures as input for program. The output of VADAR calculation regarding the side chains of residues in both solution and crystal structures are shown in Fig. 3. It can be seen that $\mathrm{Ala}^{19}$ with a hydrophobic side chain is exposed to polar environment. According to hydropathy score table of Kyte-Doolittle [19] it seems that the presence of Ala with hydropathy 
score of +1.8 is thermodynamically unfavorable. Hence; this residue was selected as the site of mutation.

\section{Fig. 3}

Structural examination of the solution state structure of Brz (pdb code:2LY5) with PIC server shows that side chain of $\mathrm{Ala}^{19}$ interacts with the main chains of $\mathrm{Asn}^{23}$ and $\mathrm{Glu}^{36}$. More Exact structural examination by conversion of pdb files to DSSP file format indicate that $\mathrm{Ala}^{19}$ is involved in helix and turn conformers in solution and crystal structures, respectively.

In the first mutation named A19K, $\mathrm{Ala}^{19}$ was replaced by Lys which has hydropathy score of 3.9. In the second one named A19D, Ala ${ }^{19}$ was replaced by Asp with hydropathy score of -3.5 . In other mutant $\mathrm{Ala}^{19}$ was substituted by Gly with more conformational space and hydropathy score of -0.4 .

\subsection{Docking}

Fig. 4, A shows the representative model of the complexed form of Brz with Sweet taste receptor subunits indicating that Brz has been optimally fitted in the cavity of the T1R2-T1R3 heterodimer containing residues of both subunits. Proximal residues from the subunits at the contact interface are also shown in Fig. 4, B.

Fig. 4

In order to compare the complexed forms of Brz and its mutants and for determining the structure-function relationship, all interacting residues in contact surface for WT brazzein and its mutants are shown in Fig. 5.

Fig. 5

\subsection{Expression and purification of the WT and mutant proteins}

In heterologous expression in E. coli strain SHuffle ${ }^{\circledR} \mathrm{T} 7$ Express, approximately 7.2-8.4 $\mathrm{mg} / \mathrm{L}$ of WT and mutant forms of Brz was obtained. We evaluated the purity of expressed proteins by Tris-Tricine gel SDS-PAGE electrophoresis. Fig. 6 shows the results of Tris-Tricine 
gel electrophoresis which reveal soluble protein variants at high level of purity. This level of purity is essential for Sweetness Assessment and spectroscopic studies.

Fig. 6

\subsection{Sweetness Assessment}

The results of taste panel test for WT protein and its mutants are shown in Fig. 7.

\section{Fig. 7}

Sweetness power of WT protein and its mutants was also compared with sucrose and the results are provided in Table 2.

Table 2.

According to data of Fig. 7 it was revealed that the substitution of alanine 19 with glycine could not alter the sweetness potency of Brz; while, A19G variant has the same activity as WT protein. However, introduction of a positive charge in A19K mutant led to 4-fold increase in Brz's sweetness. On the other hand, substitution of alanine with negative-charged residue in A19D mutant results in decreasing the activity of protein and reduction of its sweetness power. The resulting data of Table 2 are also in good agreement with those provided in Fig. 7.

\subsection{Circular Dichroism measurement}

We used far UV CD measurement for monitoring the changes in the secondary structure of protein upon mutation. The far UV CD spectra (Fig. 8) have a characteristic shape of beta-sheet structure with different magnitudes for WT protein and mutants.

Fig. 8 
According to far UV CD spectra of Fig. 8, hypochromacity of CD band with a slight red shift in the position of the negative band was observed for A19D and A19K mutants. The hypochromacity of CD band in A19D and A19K relative to WT and A19G mutant is originated from the more flexibility of peptide bonds. This is because that peptide bonds act as chromophores in far UV-CD region. On the other hand, beta sheets in proteins have a wide range of extended geometries and flexibility. The variation in beta sheets can occur in length and width as well as twisting angle and in globular protein they may deviate from the planar structure [44].

Hence, resulting CD data spectra indicates that presence of Gly with more conformational space (local flexibility) could help the beta strands for better orientation and obtaining appropriate geometry for creation of optimized intra-strand hydrogen bonds essential for formation of beta sheet structure toward global stabilization of protein. In other words, although the physico-chemical properties of Gly may results in local instability as a result of more local flexibility, however, the global stability of Brz increases in A19G mutant because of optimizing the geometries of beta strands and intra-strands hydrogen bonds.

The small red shift in CD band in A19D and A19K mutants can be attributed to the more favorable interaction of dipole moment of Asp and Lys with polar solvent molecules.

\subsection{Isothermal urea induced unfolding}

In equilibrium unfolding studies, we assumed a two state unfolding mechanism for Brz. In this assumption both native (N) and unfolded (D) conformations are present at measurable concentrations and there is no stable intermediate in equilibrium [45]. It is noticeable that upon chemical unfolding at different concentrations of urea, the fluorescence spectroscopy was used for monitoring the changes in the tertiary structure of protein around chromophores which are involved in fluorescence emission. Brz contains no tryptophan (Trp) residue. However, it has 6 tyrosines (Tyr) at positions 8, 11, 24, 39, 51 and 54. It has also a single Phenyl-alanine (Phe)

residue (Phe38) near Tyr39. Hence, the fluorescence emission of Brz is originated mainly from Tyr residues and our interpretation of the conformational stability is related to these locations of protein. Fig. 9 shows the equilibrium denaturation curves of WT and mutants as the $\lambda_{\max }$ of fluorescence emission against the denaturant concentrations. The continuous lines for each scatter-plot are the best fit of experimental data to equation 3 . 
Fig. 9.

Thermodynamic parameters of isothermal denaturation experiments obtained from the analysis of data in Fig. 9 are given in Table 3.

Table 3.

According to equilibrium unfolding data in Table 3; the conformational stability of WT-Brz against urea denaturation in the absence of disulfide bonds is only $1.97 \mathrm{kcal} / \mathrm{mol}$. The $\mathrm{m}$-value has been shown to be proportional to the difference in the solvent accessible surface area (SASA) between the denatured and folded states of protein. Comparison of [urea $]_{50 \%}$ and thermodynamic m-values in table 3 suggests that more stability of A19G is more related to [urea $]_{50 \%}$; while, higher magnitude of $\mathrm{m}$-value in A19D as destabilized variant is originated from its higher SASA in denatured state rather than its compactness in the folded state.

\section{Discussion}

Dssp file contents of the solution structure of Brz (pad code: 2LY5) indicate that a fragment of protein ranging from $\mathrm{Ala}^{19}$ to $\mathrm{Lys}^{30}$ is the only helix conformation in the structure of Brz. Furthermore, $\mathrm{Ala}^{19}$ is located at the starting point of this helix between hydrophobic Leu and polar Asn residues. According to the bioinformatic studies and modelling results we found that non-polar $\mathrm{Ala}^{19}$ is located at the surface of protein near polar environment which apparently is in contrast with physico-chemical principles. So, we assumed that replacement of Ala ${ }^{19}$ with more hydrophilic residues may influence both conformational stability of Brz as well as its interaction with receptors.

According to the results of theoretical and far UV-CD studies on WT and mutants, it seems that Asp and Lys residues in A19D and A19K variants are directly involved in hydrogen bonds with other residues as well as polar water molecules. However, these interactions lead to distortion of beta strands and decreasing the stability of beta sheets or overall conformational stability of protein. In contrast, high degree of local flexibility in A19G mutant is accompanied by increased overall conformational stability of protein. these findings with Taste test results together indicates that local flexibility and positive charge at the surface of protein are more 
important factors influencing the interaction of protein with the G-protein coupled human sweet receptor.

According to docking results, the side of protein containing position 19 is toward interacting surface of receptor for all protein variants (Fig. $4 \& 5$ ). This is in good agreement with the report of Singarapu et al [20] in which they considered the region of protein containing position 19 as one of the critical points for interaction with the receptor. Hence, it seems that any change in this position may alter the stability of the corresponding complex.

Comparison of the complexed forms of WT Brz and its mutants (Fig. 5) indicate that increasing of sweet taste in A19K mutant is associated with significant change in the number and pattern of weak interactions at the binding surface. Structural examination of modeled complex of E19Kreceprore indicates that positive side chain of $\mathrm{Lys}^{19}$ in $\mathrm{A} 19 \mathrm{~K}$ mutants has 13.43 and 13.35 angstrom distance from negative side chains of $\mathrm{Glu}^{252}$ and $\mathrm{Glu}^{253}$, respectively. It seems that the presence of negatively electrostatic patch including $\mathrm{Glu}^{252}-\mathrm{Glu}^{253}$ in T1R2 subunit results in creation of a long-range electrostatic interaction with positive side chain of Lys at position 19 of A19K mutant which in turn elicit to slight chain mobility of protein at the binding surface and changing the pattern of interactions toward more effective binding. Structural data of Fig. 5 shows that among 14 different types of weak interactions, WT Brz has only one ionic interaction including Lys ${ }^{15}$-Asp ${ }^{520}$-T1R3 and upon replacement of Ala with Lys in A19K mutant Glu ${ }^{253}$ and $\mathrm{His}^{50}$ of T1R2 can also form ionic interactions with corresponding residues in A19K (Lys ${ }^{15}$ $\mathrm{Asp}^{520}-\mathrm{T} 1 \mathrm{R} 3, \mathrm{Lys}^{15}-\mathrm{Glu}^{253}-\mathrm{T} 1 \mathrm{R} 2$ and $\left.\mathrm{Asp}^{25}-\mathrm{His}^{50}-\mathrm{T} 1 \mathrm{R} 2\right)$. This finding indicates that Lys at position 19 is indirectly involved in binding process. It was also found that some of the binding interactions including Lys ${ }^{15}-\mathrm{Tyr}^{519}-\mathrm{T} 1 \mathrm{R} 3, \mathrm{Tyr}^{24}-\mathrm{Gln}^{255}-\mathrm{T} 1 \mathrm{R} 2, \mathrm{Tyr}^{39}-\mathrm{Trp}^{487}-\mathrm{T} 1 \mathrm{R} 3$, Tyr ${ }^{39}-\mathrm{His}^{488}$ T1R3 as well as $\mathrm{Arg}^{43}$ - His ${ }^{488}$-T1R3 are removed and new ones are formed with $\mathrm{Val}^{13}, \mathrm{Ser}^{14}$, $\mathrm{Glu}^{17}, \mathrm{Leu}^{18}, \mathrm{Asp}^{25}$ and Leu ${ }^{45}$ in A19k mutants which finally results in increasing the number of interactions to 19. This leads to enhancement of binding strengths of E9K variant with sweet receptor and especially T1R2 subunit. Similar examination of interactions in A19G and A19D variants indicates that the number of weak interactions in A19G and A19D mutants is 13 and 12, respectively. These data together indicate that sweetness of protein can be changed by altering the number and pattern of interactions at binding surface. According to the results of isothermal denaturation experiments, it appears that interaction of A19D and A19K variants with urea molecules is more favorable than A19G and WT. This is because that urea molecule can interact 
with protein by forming hydrogen bonds with surfaced exposed residues of protein and/or by exchanging hydrogen bonds with intra-molecular hydrogen bonds. Hence, the ability of Asp and Lys to form hydrogen bond with water molecules in the absence of urea and replacing these bonds with urea molecules in denaturing conditions can help protein to denature more favorably relative to WT and A19G mutant. By following the same reasoning, it may be concluded that the absence of side chain in Gly results in more stability of A19G mutants against urea denaturation. Considering previously reports on high degree of thermal stability of Brz and its low chemical stability; we reported in this study, it may be said that the presence of disulfide bonds has profound effect on the structural integrity of Brz. In summary, antithetical effect of A19D and A19K mutants on the activity of protein and similar activity observed for WT and A19G variant indicate that the presence of charged residue at this position may have profound effect on the interaction of protein with corresponding receptor. It was also concluded that positive charge at this position can increases the strength of interaction toward increasing the sweetness power of protein; while, negative charge decreases the activity of protein.

Our data are in good agreement with previously reports concerning the importance of positive charge on the activity and sweetness of protein in regions of protein other than that we investigated in this study. Accordingly; it can be concluded that $\mathrm{Ala}^{19}$ can be considered as a critical region for investigating the relationship between structure and activity of Brz.

\section{Acknowledgments}

Financial support of this work was provided by Iran National Science Foundation (Fund Number: 90007290). We would also like to thank the Research Council of the University of Zanjan. We also appreciate technical support from Institute of Biochemistry and Biophysics (IBB) of the university of Tehran and Institute for Advanced Studies in Basic Sciences of Zanjan for Circular Dichroism and fluorescence measurements, respectively. The authors have declared no conflict of interest

\section{Reference}

[1] C. Johnston, B. Stevens, J. Foreyt, The role of low-calorie sweeteners in diabetes, US Endocrinol 2 (2013) 96-98. 
[2] K. Ishikawa, M. Ota, Y. Ariyoshi, H. Sasaki, M. Tanokura, D. Ming, J. Caldwell, F. Abilgaad, Crystallization and preliminary X-ray analysis of brazzein, a new sweet protein, Acta Crystallographica Section D: Biological Crystallography 52 (1996) 577-578.

[3] M. Kohmura, M. Ota, H. Izawa, M. Hellekant, D. Göran, Y. Ariyoshi, Assignment of the disulfide bonds in the sweet protein brazzein, Biopolymers 38 (1996) 553-556.

[4] C.C. Cornilescu, G. Cornilescu, H. Rao, S.F. Porter, M. Tonelli, M.L. DeRider, J.L. Markley, F.M. Assadi-Porter, Temperature-dependent conformational change affecting Tyr11 and sweetness loops of brazzein, Proteins: Structure, Function, and Bioinformatics 81 (2013) 919-925.

[5] D. Ming, G. Hellekant, Brazzein, a new high-potency thermostable sweet protein from Pentadiplandra brazzeana B, FEBS letters 355 (1994) 106-108.

[6] K. Nagata, N. Hongo, Y. Kameda, A. Yamamura, H. Sasaki, W.C. Lee, K. Ishikawa, E.-i. Suzuki, M. Tanokura, The structure of brazzein, a sweet-tasting protein from the wild African plant Pentadiplandra brazzeana, Acta Crystallographica Section D: Biological Crystallography 69 (2013) 642-647.

[7] F.M. Assadi-Porter, F. Abildgaard, H. Blad, C.C. Cornilescu, J.L. Markley, Brazzein, a small, sweet protein: effects of mutations on its structure, dynamics and functional properties, Chemical senses 30 (2005) i90-i91. [8] F.M. Assadi-Porter, F. Abildgaard, H. Blad, J.L. Markley, Correlation of the sweetness of variants of the protein brazzein with patterns of hydrogen bonds detected by NMR spectroscopy, Journal of Biological Chemistry 278 (2003) 31331-31339.

[9] F.M. Assadi-Porter, D.J. Aceti, J.L. Markley, Sweetness determinant sites of brazzein, a small, heat-stable, sweet-tasting protein, Archives of biochemistry and biophysics 376 (2000) 259-265.

[10] F.M. Assadi-Porter, M. Tonelli, E. Maillet, K. Hallenga, O. Benard, M. Max, J.L. Markley, Direct NMR detection of the binding of functional ligands to the human sweet receptor, a heterodimeric family 3 GPCR, Journal of the American Chemical Society 130 (2008) 7212-7213.

[11] F.M. Assadi-Porter, M. Tonelli, E.L. Maillet, J.L. Markley, M. Max, Interactions between the human sweet-sensing T1R2-T1R3 receptor and sweeteners detected by saturation transfer difference NMR spectroscopy, Biochimica et Biophysica Acta (BBA)-Biomembranes 1798 (2010) 82-86.

[12] Z. Jin, V. Danilova, F.M. Assadi-Porter, D.J. Aceti, J.L. Markley, G. Hellekant, Critical regions for the sweetness of brazzein, FEBS letters 544 (2003) 33-37.

[13] Z. Jin, V. Danilova, F.M. Assadi-Porter, J.L. Markley, G. Hellekant, Monkey electrophysiological and human psychophysical responses to mutants of the sweet protein brazzein: delineating brazzein sweetness, Chemical senses 28 (2003) 491-498.

[14] H.-D. Do, H.-J. Jo, D.-H. Jo, K.-H. Kong, Mutagenesis of critical amino acid residues in $\alpha$-helix and $\beta$ sheet structures of brazzein, Bulletin of the Korean Chemical Society 32 (2011) 4106-4108.

[15] J.-W. Lee, J.-E. Cha, H.-J. Jo, K.-H. Kong, Multiple mutations of the critical amino acid residues for the sweetness of the sweet-tasting protein, brazzein, Food chemistry 138 (2013) 1370-1373.

[16] D.E. Walters, T. Cragin, Z. Jin, J.N. Rumbley, G. Hellekant, Design and evaluation of new analogs of the sweet protein brazzein, Chemical senses 34 (2009) 679-683. 
[17] S.-Y. Yoon, J.-N. Kong, D.-H. Jo, K.-H. Kong, Residue mutations in the sweetness loops for the sweettasting protein brazzein, Food Chemistry 129 (2011) 1327-1330.

[18] P.J. Fleming, F.M. Richards, Protein packing: dependence on protein size, secondary structure and amino acid composition, Journal of molecular biology 299 (2000) 487-498.

[19] J. Kyte, R.F. Doolittle, A simple method for displaying the hydropathic character of a protein, Journal of molecular biology 157 (1982) 105-132.

[20] K.K. Singarapu, M. Tonelli, J.L. Markley, F.M. Assadi-Porter, Structure-function relationships of brazzein variants with altered interactions with the human sweet taste receptor, Protein Science. 25 (2016) 711-719.

[21] S.S. Jafari, V. Jafarian, Kh. Khalifeh, P. Ghanavatian, S.A. Shirdel, The effect of charge alteration and flexibility on the function and structural stability of seet-tasting Brazzein, RSC Advances. 6 (2016) 59834-59841.

[22] J. Sambrook, E.F. Fritsch, T. Maniatis, Molecular cloning, Cold spring harbor laboratory press New York, Vol. 2, 1989.

[23] M.M. Bradford, A rapid and sensitive method for the quantitation of microgram quantities of protein utilizing the principle of protein-dye binding, Analytical biochemistry 72 (1976) 248-254.

[24] F.M. Assadi-Porter, D.J. Aceti, H. Cheng, J.L. Markley, Efficient production of recombinant brazzein, a small, heat-stable, sweet-tasting protein of plant origin, Archives of biochemistry and biophysics 376 (2000) 252258.

[25] Y.A. Andreev, S.A. Kozlov, A.A. Vassilevski, E.V. Grishin, Cyanogen bromide cleavage of proteins in salt and buffer solutions, Analytical biochemistry 407 (2010) 144-146.

[26] J.-J. Lee, J.-N. Kong, H.-D. Do, D.-H. Jo, K.-H. Kong, Design and efficient soluble expression of a sweet protein, brazzein and minor-form mutant, Bulletin of the Korean Chemical Society 31 (2010) 3830-3833.

[27] A. Fiser, A. Sali, Modeller: generation and refinement of homology-based protein structure models, Methods in enzymology 374 (2003) 461-491.

[28] T. Moto, D. Tsuchya, K. Morikawa, H. Jingami, Crystal structure of the extracellular region of the group II metabotropic glutamate receptor complexed with L-glutamate, Proc.Natl.Acad.Sci.USA 104 (2007) 3759-3764.

[29] J.U. Bowie, R. Luthy, D. Eisenberg, A method to identify protein sequences that fold into a known threedimensional structure, Science 253 (1991) 164-170.

[30] C. Colovos, T.O. Yeates, Verification of protein structures: patterns of nonbonded atomic interactions, Protein Science 2 (1993) 1511-1519.

[31] R.A. Laskowski, M.W. MacArthur, D.S. Moss, J.M. Thornton, PROCHECK: a program to check the stereochemical quality of protein structures, Journal of applied crystallography 26 (1993) 283-291.

[32] J. Pontius, J. Richelle, S.J. Wodak, Deviations from standard atomic volumes as a quality measure for protein crystal structures, Journal of molecular biology 264 (1996) 121-136.

[33] F. Melo, R. Sánchez, A. Sali, Statistical potentials for fold assessment, Protein science 11 (2002) 430-448.

[34] M.y. Shen, A. Sali, Statistical potential for assessment and prediction of protein structures, Protein science 15 (2006) 2507-2524. 
[35] D. Eramian, N. Eswar, M.Y. Shen, A. Sali, How well can the accuracy of comparative protein structure models be predicted?, Protein Science 17 (2008) 1881-1893.

[36] L. Willard, A. Ranjan, H. Zhang, H. Monzavi, R.F. Boyko, B.D. Sykes, D.S. Wishart, VADAR: a web server for quantitative evaluation of protein structure quality, Nucleic acids research 31 (2003) 3316-3319.

[37] K. Tina, R. Bhadra, N. Srinivasan, PIC: protein interactions calculator, Nucleic acids research 35 (2007) W473-W476.

[38] G.C.P van Zundert, J.P.G.L.M. Rodrigues, M. Trellet, C. Schmitz, P.L. Kastritis, E. Karaca, A.S.J. Melquiond, M. van Dijk, S.J. de Vries, The HADDOCK2.2 webserver: User-friendly integrative modeling of biomolecular complexes, J. Mol. Biol 482 (2015) 720-725.

[39] P.A. Temussi, Why are sweet proteins sweet? Interaction of brazzein, monellin and thaumatin with the T1R2-T1R3 receptor, FEBS Lett.28 (526) (2002) 1-4.

[40] F.M. Assadi Porter, E.L. Maillet, J.T, Radek, J. Quijada, J.L. Markley, M, Max, Key amino acid residues involved in multi-point binding interactions between brazzein, a sweet protein, and the T1R2-T1R3 human sweet receptor, J Mol Biol 14: 398 (4) (2010) 584-599.

[41] C. Pace, Determination and analysis of urea and guanidine hydrochloride denaturation curves in Methods Enzymol.(Hirs, CHW and Timasheff, SN, eds.) Vol. 131, Academic Press, New York, 1985.

[42] M.M. Santoro, D. Bolen, Unfolding free energy changes determined by the linear extrapolation method. 1. Unfolding of phenylmethanesulfonyl. alpha.-chymotrypsin using different denaturants, Biochemistry 27 (1988) 8063-8068.

[43] V.R. Agashe, J.B. Udgaonkar, Thermodynamics of denaturation of barstar: evidence for cold denaturation and evaluation of the interaction with guanidine hydrochloride, Biochemistry 34 (1995) 3286-3299.

[44] F. Salemme, Structural properties of protein $\beta$-sheets, Progress in biophysics and molecular biology 42 (1983) 95-133.

[45] C.N. Pace, K.L. Shaw, Linear extrapolation method of analyzing solvent denaturation curves, Proteins: Structure, Function, and Bioinformatics 41 (2000) 1-7. 


\section{Table and Legends}

Table 1 Selective residues for substitution by site-directed mutagenesis and modified brazzein residues; Changed base are shown by bold and underline.

Table 2 The comparison between the sweetness intensity of WT protein brazzein and its mutants with sucrose.

Table 3 Thermodynamic parameters for WT brazzein and mutants obtained by analysis of equilibrium denaturation curves of Figure 7 using equation 1.

\section{Table1}

\begin{tabular}{ccccc}
\hline Position & $\begin{array}{c}\text { Residue } \\
\text { substitution }\end{array}$ & & \multicolumn{2}{c}{ Residue character } \\
\cline { 4 - 5 } Before & After & Primer Sequence & Before & after \\
\hline Ala 19 & Gly & tccaaatgtcagctgggcaaccagtgcaactac & Uncharged \\
& Asp & caaatgccagcttgacaaccagtacaactac & Uncharged & Negative \\
& lys & gtccaaatgccagctgaaaaaccagtgcaactacg & & Positive \\
\hline
\end{tabular}

Table2

\begin{tabular}{|c|c|c|c|c|c|}
\hline \multirow[t]{2}{*}{$\begin{array}{l}\text { Sweet tasting } \\
\text { molecule }\end{array}$} & \multirow[t]{2}{*}{$\begin{array}{l}\text { Molecular mass } \\
\text { (Da) }\end{array}$} & \multicolumn{2}{|c|}{$\begin{array}{l}\text { Experimental taste } \\
\text { threshold }\end{array}$} & \multicolumn{2}{|c|}{$\begin{array}{c}\text { Sweetness in comparison to } \\
\text { Sucrose }\end{array}$} \\
\hline & & 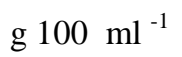 & $\mu \mathrm{M}$ & $g / g$ & Molecule \\
\hline Sucrose & 342.30 & 1 & 29000 & 1 & 1 \\
\hline WT & 6370.19 & 0.0004 & 0.6279 & 2510 & 46711.81 \\
\hline A19K & 6427.29 & 0.0001 & 0.1555 & 10025 & 188237.16 \\
\hline A19G & 6356.16 & 0.0004 & 0.629 & 2510 & 46711.81 \\
\hline A19D & 6414.20 & 0.001 & 1.559 & 985 & 18457.45 \\
\hline
\end{tabular}


Table 3

\begin{tabular}{|c|c|c|c|}
\hline Protein variants & ${ }^{\mathrm{a}} \Delta \mathrm{G}_{(\mathrm{H} 2 \mathrm{O})}$ & ${ }^{\mathrm{a}} \mathrm{m}$-value & {$[\text { Urea }]_{50 \%}$} \\
\hline WT & $1.97 \pm 0.09$ & $0.52 \pm 0.02$ & $3.79 \pm 0.22$ \\
\hline A19D & $1.73 \pm 0.07$ & $0.60 \pm 0.03$ & $2.88 \pm 0.18$ \\
\hline A19K & $1.51 \pm 0.05$ & $0.52 \pm 0.02$ & $2.90 \pm 0.15$ \\
\hline A19G & $2.03 \pm 0.09$ & $0.44 \pm 0.03$ & $4.61 \pm 0.37$ \\
\hline $\begin{array}{r}{ }^{\mathrm{a}} \text { Standard } \\
\text { In quantitative analys } \\
\text { change of protein in } \\
\text { concentr }\end{array}$ & $\begin{array}{l}\mathrm{kcal}^{\mathrm{mol}}{ }^{-2} \\
\text { s) are calc } \\
\text { uration cur } \\
\text { ion at diffe } \\
\text { fitting exp }\end{array}$ & $\begin{array}{l}\text { nd } \Delta \mathrm{G}_{(\mathrm{H} 2 \mathrm{O})} \mathrm{i} \\
\text { ree or four } \mathrm{r} \\
\text { perimental } \\
\text { of urea is th } \\
\text { equation } 3 \mathrm{a}\end{array}$ & $\begin{array}{l}\text { ments. } \\
\text { 3. The free energy } \\
\text { olated to the zero } \\
(\mathrm{H} 2 \mathrm{O}) \text {. }\end{array}$ \\
\hline
\end{tabular}




\section{Figure Legends}

Figure 1. Insertion of the gene responsible for coding of the minor form of brazzein in pET 28a (A) Unique sites are shown on the circle map in pET 28a (B) protein sequence of minor form of brazzein, His-Tag, cleavage $\mathrm{CNBr}$ site and position A19.

Figure 2. Ribbon diagram of Brazzein in Crystal state (A) and solution state (B) determined by X-Ray Crystallography (PDB code: 4HE7) and Nuclear Magnetic Resonance (PDB code: 2LY5), respectively. The site of mutation is shown by white arrow. (The structure is depicted by Chimera software).

Figure 3. Accessible Surface Area of the side chains of Brazzein residues in solution state structure (dotted line) and crystal structure (continuous line). The pdb files of protein in solution and crystal states (PDB code: 2LY5 and 4HE7, respectively) was used as input for calculation the ASA in VADAR.

Figure 4. Representation of the interaction of WT brazzein with the subunits of the hetero-dimeric human sweet receptor. HADDOCK program was used for construction of complexes. (A) space-filling model, with the T1R2 protomer colored in blue and the T1R2 in green and brazzein in red. (B) Close-up view as ribbon scheme and details of binding sites of brazzein with regions of T1R2 and T1R3 showing the critical residues at the interacting surface.

Figure 5. Regions of predicted complexes of the modeled structure of T1R2-T1R3 sweet receptor with brazzein and its mutants containing the interacting residues at the binding surface of the receptor cavity. Residues of the T1R2, T1R3 and brazzein are shown in blue, green and red respectively. The selected models were evaluated by PIC server for determining different types of interactions at the binding surface. The Hydrophobic, Ionic, Aromatic-Sulphur and Cation-Pi interactions were calculated within 5, 6, 5.3 and 6 Angstroms, respectively. While Aromatic-Aromatic interactions were calculated within 4.5 and 7 Angstroms.

Figure 6. Tris-Tricine gel analysis of protein variants after purification with affinity Ni-NTA column chromatography.

Figure 7. The results of taste panel for WT mutants. The results are gathered from 11 people and are reported with corresponding errors. The black color and hatched columns refers to WT and mutant proteins, respectively. DW refers to distilled water.

Figure 8. Far UV CD spectra of WT brazzein and its mutants. Far-UV CD spectra were recorded at a protein concentration of $0.2 \mathrm{mg} / \mathrm{ml}$ in the wavelengths ranging from 190 to $250 \mathrm{~nm}$. The spectra were analyzed by Jasco program and are expressed as mean residue ellipticity.

Figure 9. Normalized equilibrium denaturation curves of the WT Brazzein and its mutants monitored by $\lambda_{\max }$ of fluorescence intensity. the experimental data were fitted to the equation 3 by kaliedagraph analysis software. 
Figures

Fig. 1

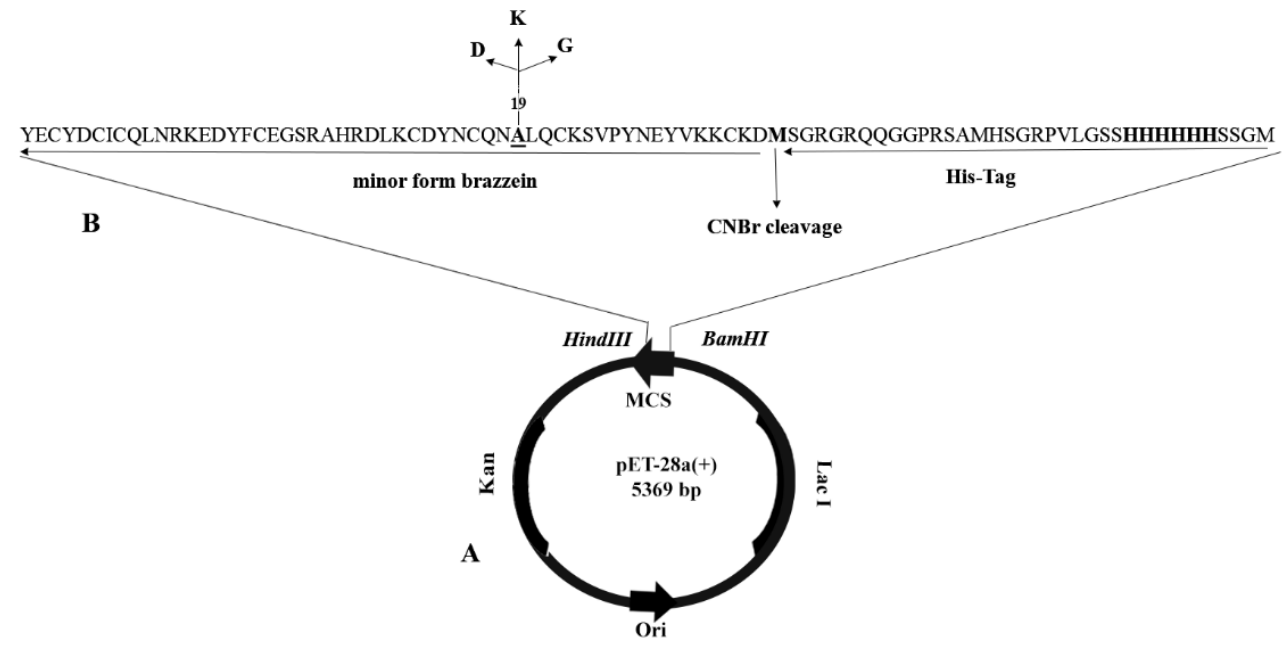

Fig. 2

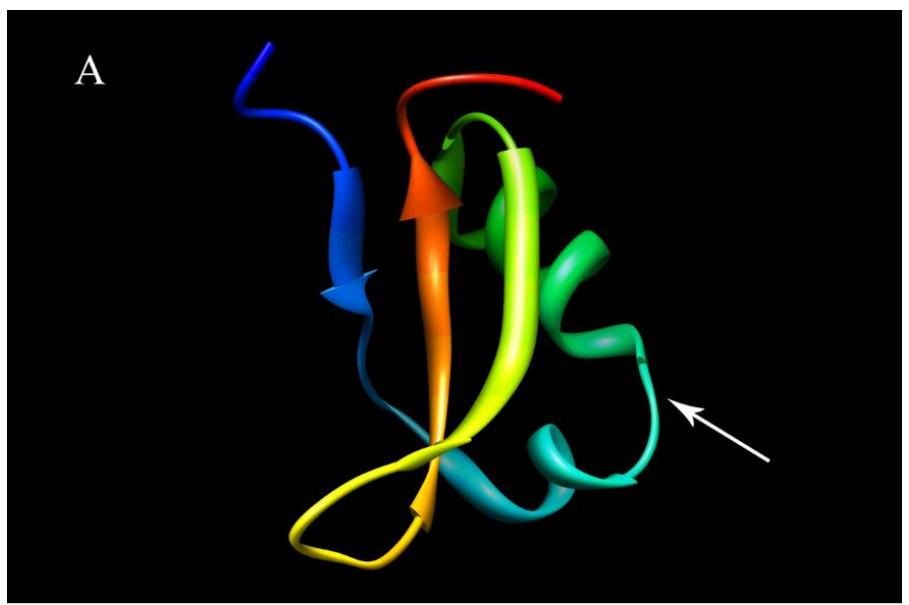

B

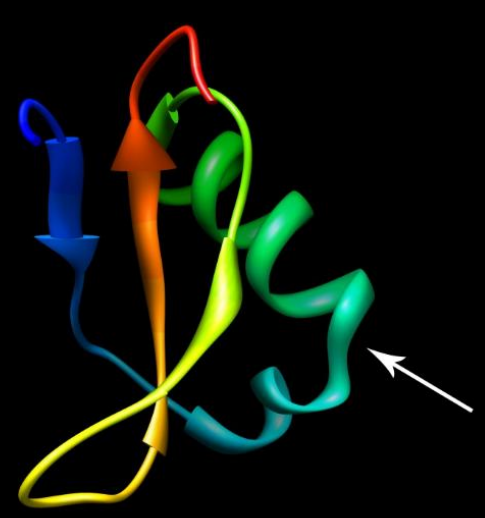


Fig. 3

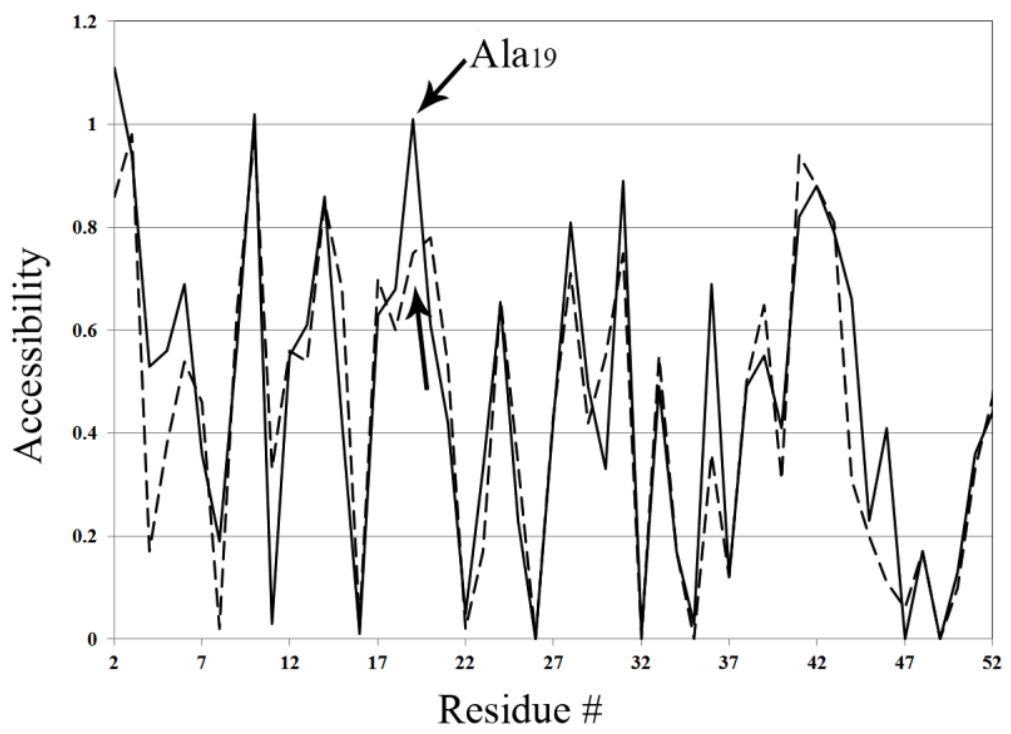

Fig. 4
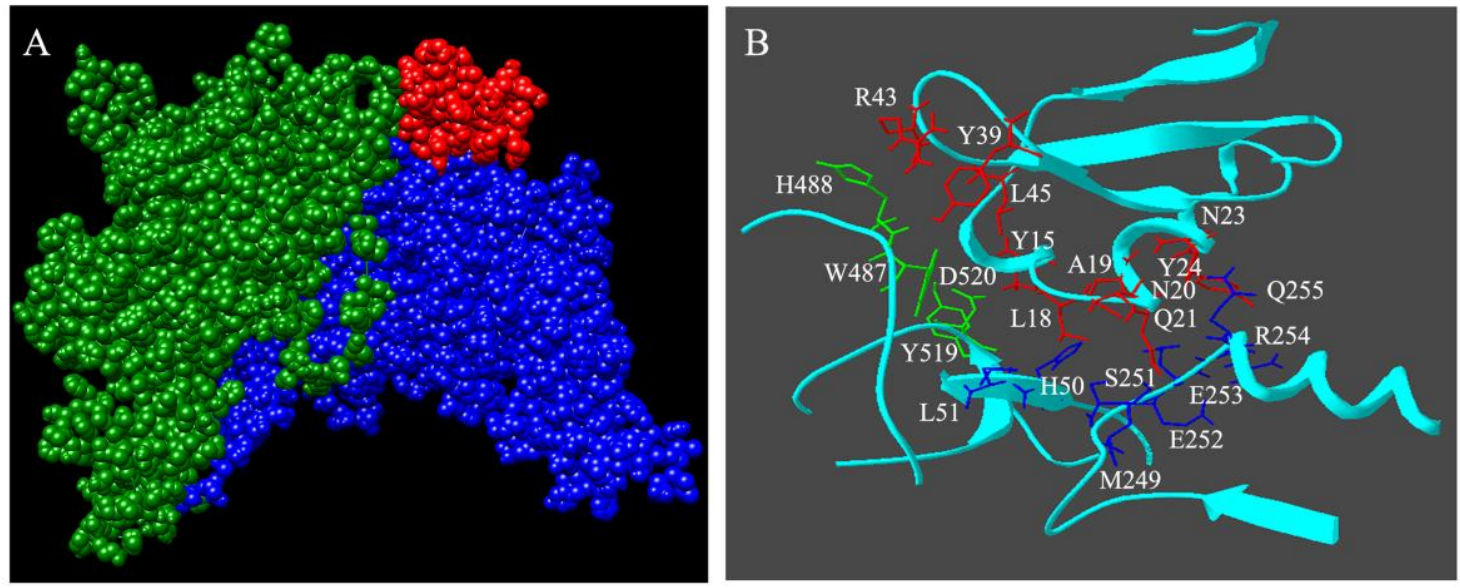
Fig. 5
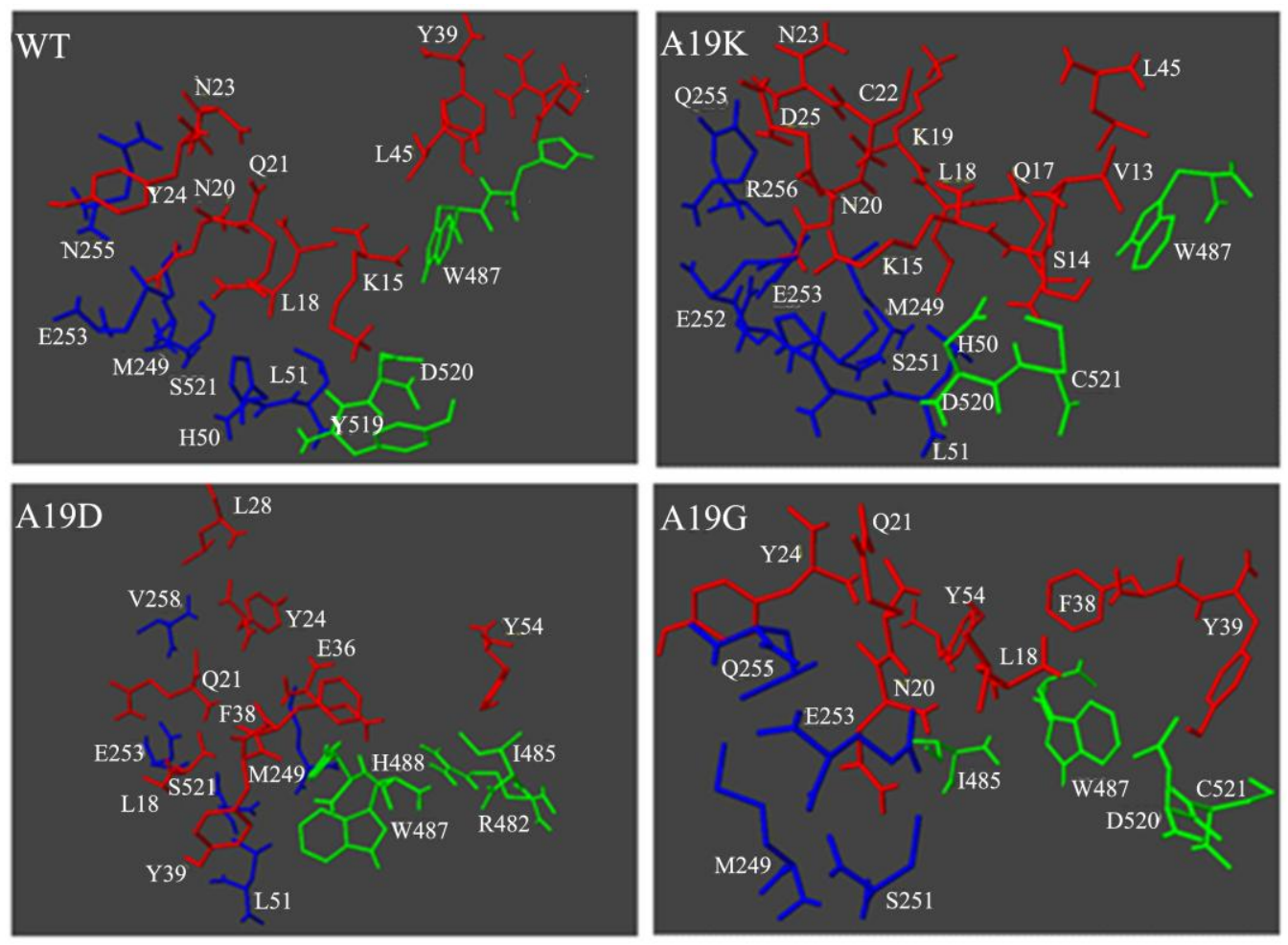

Fig. 6

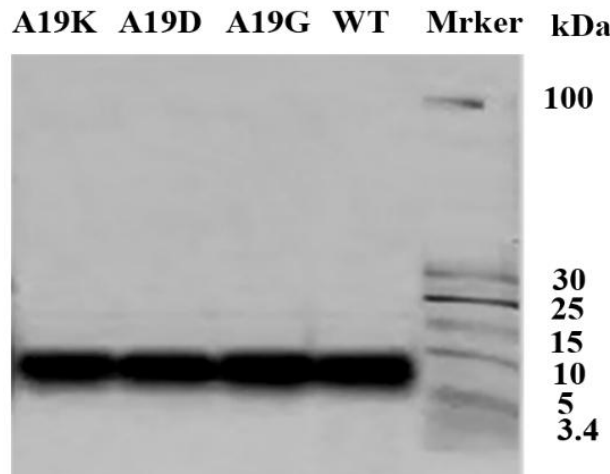


Fig. 7

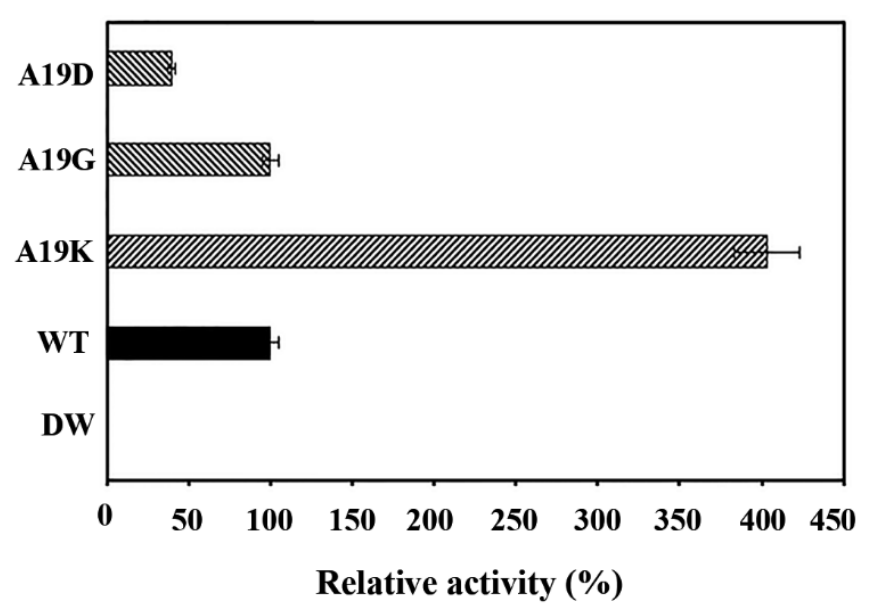

Fig. 8

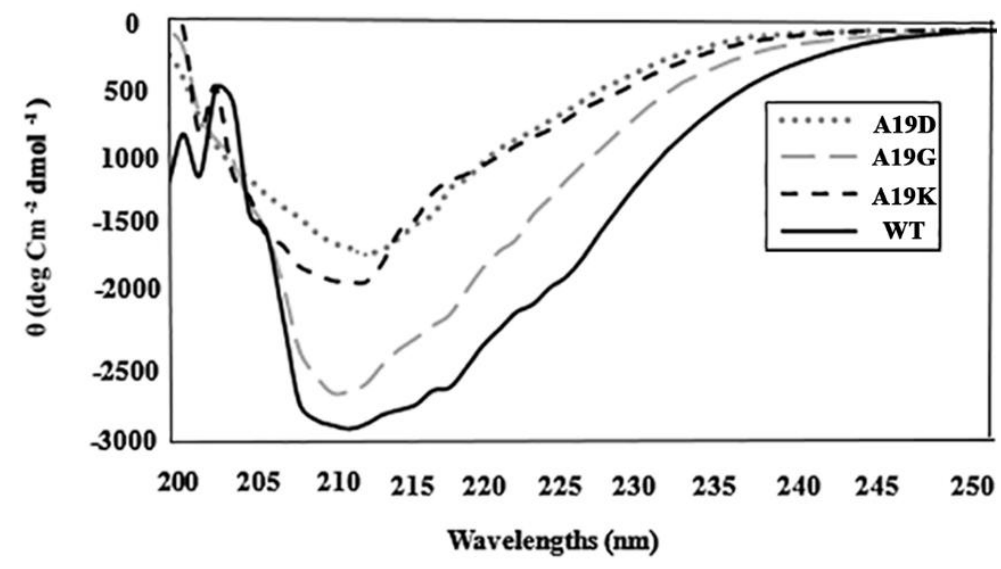


Fig. 9

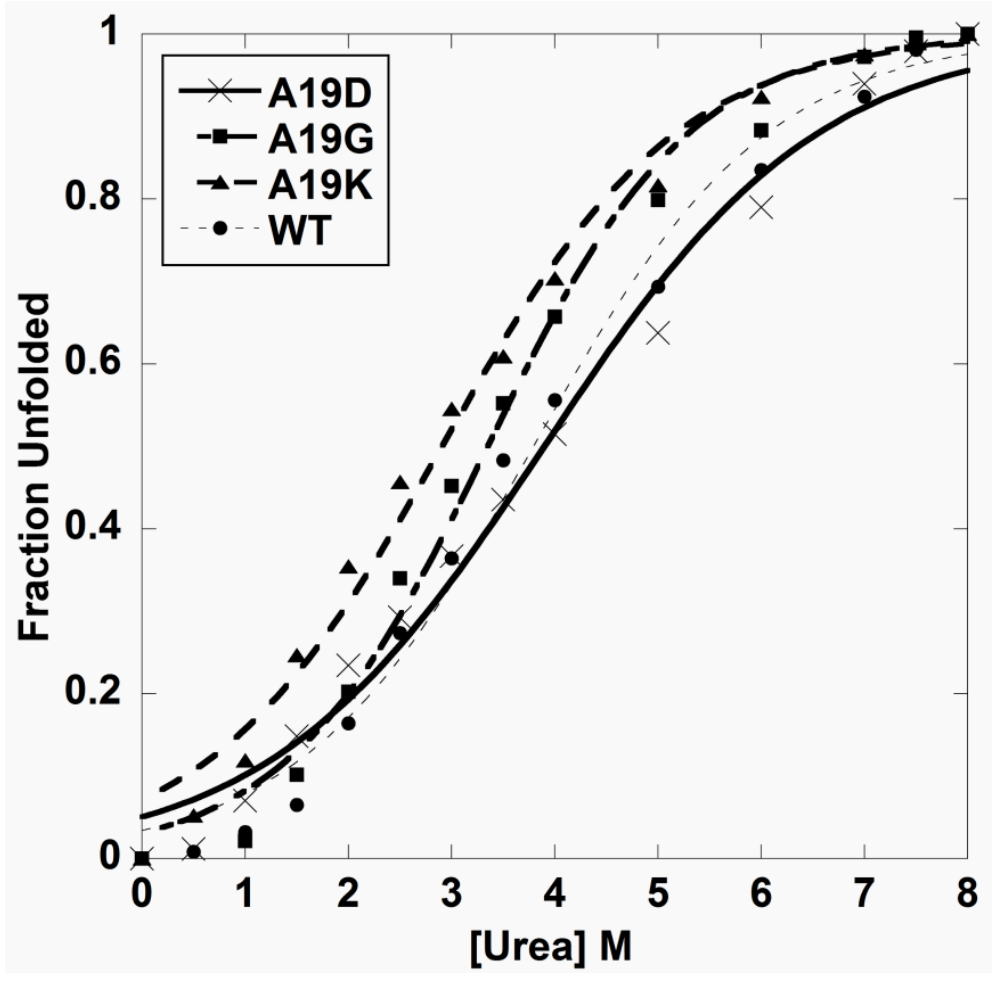

